\title{
New Geodetic Infrastructure for Australia
}

\section{The University Component of the AuScope Geospatial Team*}

*To whom correspondence should be addressed; E-mail: Paul.Tregoning@anu.edu.au

1

\begin{abstract}
In November 2006, the Australian Federal Government announced $\$ 15.8 \mathrm{M}$ in funding for geospatial research infrastructure through the National Collaborative Research Infrastructure Strategy (NCRIS). NCRIS is an initiative under the Australian Government's Backing Australia's Ability package with a number of key principles, including maximising the contributions of the R\&D system to economic development, national security, social wellbeing and environmental sustainability. Here we outline why particular components of geospatial infrastructure are required in Australia to advance (equip) geospatial research over the next 20 years. We describe some of the scientific objectives that required an upgrade and densification of Australia's geospatial infrastructure. This paper is the perspective from a subset of University researchers involved in the AuScope Geospatial component, so does not necessarily encompass the opinions of all those involved in AuScope Geospatial.
\end{abstract}

\section{Introduction}

The Australian National Collaborative Research Infrastructure Strategy (NCRIS) provided over $\$ 500 \mathrm{M}$ to 13 capability areas in order to "concentrate effort nationally on areas of greatest strategic impact" (NCRIS Strategic Roadmap, 2006). One of these capability areas, titled 'Structure and Evolution of the Australian Continent', comprises Earth imaging, geochemistry, numerical simulation and modelling, a virtual core library, and a significant component of geospatial infrastructure. Known collectively as AuScope, this capability area brought together Australia's leading Earth scientists to decide upon the most pressing scientific issues and geodetic infrastructure needs for studying Earth

\footnotetext{
${ }^{1}$ The following people were involved in the writing of this article and/or the geospatial component of the AuScope proposal (in alphabetical order): R. Coleman, J. Dickey, W. Featherstone, M. Higgins, G. Johnston, K. Lambeck, J. Lovell, H. McQueen, C. Rizos, S. Tingay, P. Tregoning, B. Twilley, C. Watson.
} 
systems and their impact on the Australian continent, yet at the same time endeavoured to position Australian geodetic science capability at international standards into the future.

The geospatial component of AuScope received $\$ 15.8 \mathrm{M}$ of direct funding through the NCRIS process, but also includes a significant component of both in-kind and coinvestment from universities and State/Territory and Federal government departments. The geospatial infrastructure to be acquired includes absolute and tidal gravimeters, radio telescopes to be used for geodetic Very Long Baseline Interferometry (VLBI), a continentwide network of continuously operating Global Navigation Satellite System (GNSS) receivers, Satellite Laser Ranging (SLR) instruments, as well as the associated operating costs for all these components. Funding is provided until the end of June 2011.

Investment in geospatial infrastructure will permit Australian Earth scientists to address scientific issues such as sea-level variation and its effect on the Australian coastline, estimating the stress and strain field of the continent - with direct links to earthquake hazards, risk to large-scale urban infrastructure, elastic response of the crust to ocean and gravitational loads, defining an accurate height datum as well as to improve the accuracy of the geospatial reference frame that underpins much of society's scientific research and economic activities (the latter is estimated to be valued at $\$ 60-90$ billion/year for Canada (BearingPoint, 2004)). Improved reference frames will support positioning applications ranging from vehicle/aircraft tracking systems through to automated agricultural and mining machine guidance.

The scientific research that will utilise this new geospatial infrastructure in Australia links succinctly with other components of the AuScope priority area, primarily by providing the means to capture changes in the Earth system at current (i.e., real-time to decadal) timescales. This fills the gap between the seismic (earthquakes - instantaneous) and geological (millions of years) timescales of the other areas of the AuScope project. Geospatial studies provide the capability to measure directly the strain rate field of the continent, something that cannot be done in any other way. Such information will provide critical input data to constrain the numerical modelling proposed (e.g., studies envisaged 
by ACESS (Australian Computational Earth Systems Simulator) and other numerical modelling researchers) to assess the risk levels to Australia. It also links studies of seismic imaging and geochemical studies of terrane boundaries (where crustal blocks of different tectonic origins abut) in the Australian continent.

In this paper, we describe some of the scientific studies for which AuScope will provide new geospatial infrastructure. Ultimately, this infrastructure will provide the backbone of a new, integrated spatial positioning system spanning the whole Australian continent that will have applications for governments and commercial enterprises alike. This will include immediate and future needs (e.g., improved geodetic datums for Australia, mm-accurate positions for real-time vehicle, maritime and aircraft positioning/navigation), as well as providing the flexibility to adapt to new scientific research and applications that are likely to be developed in the future.

\section{Why Invest in New Geospatial Infrastructure?}

\subsection{Earth-system science}

Over the past several decades, geoscientists have become aware of the dynamic and interconnected nature of the Earth as a system, helped primarily by the rapid advance in measurement technologies. Each component of the Earth system (i.e., oceans, atmosphere, cryosphere (the Earth's ice masses and snow deposits) and solid Earth) interacts in complex ways, and it is clear that we live on a dynamic Earth. Such dynamic behaviour is evident from motions of the inner and outer core of the Earth, through mantle convection, plate tectonics, volcanic eruptions, earthquakes, coastal processes, ocean and atmospheric circulation, groundwater changes, ice sheet variations, ice shelf-ocean interactions, etc.

Space-based technologies have revolutionised our ability to measure previously unrecognised subtle changes in these Earth systems, and has led to an improved understanding of the solid and fluid Earth from regional to global scales. However, there is still much that we do not know and understand about the Earth; for instance, we are still not able to predict earthquake events, nor tsunami-generating landslides, nor are we in a 
position to quantify accurately the interaction between polar ice sheets, oceans and the solid Earth and the implications for sea-level change.

It is widely accepted that some of the most important scientific questions in the geosciences relate to defining and understanding these processes, and that such knowledge is essential for establishing a baseline for application areas. Understanding these processes is also of direct societal importance and of value to Federal, State/Territory and local agencies, since such knowledge underpins many management decisions.

\subsection{Upgrade and expand upon existing infrastructure}

Figure 1a shows the existing coverage of Australia's geospatial infrastructure, comprising one superconducting gravimeter (Mt Stromlo), two VLBI telescopes (Hobart and Parkes), two SLR instruments (Yaragadee and Mt Stromlo), and continuously operating reference station (CORS) GPS receivers that comprise the Australian Regional GPS Network (ARGN). In addition, there are many other CORS receivers that are not shown - in fact, there is no centralised record of all Federal-, State/Territory- and industry-operated CORS in Australia.

The spatial coverage of the existing instruments is not optimal, mainly because opportunitybased considerations and limited funding sources led to a somewhat piecemeal development of the infrastructure. The quality of monumentation also varies considerably from roof-mounted antennas through to ground marks attached robustly to bedrock, meaning that not all existing sites can be used for all possible applications (e.g., roof-mounted GNSS sites are not adequate if one wants to estimate sub-mm/yr deformation rates because the movement of the building itself may well dominate over any geophysical signal). The AuScope initiative now allows for a 'clean sheet' approach to be taken where the new instruments can be placed to enhance and extend upon the existing infrastructure.

In addition, some of this existing infrastructure is becoming dated and is sometimes unable to compete with international developments, thus lessening the quality of the contribution that Australia can make to the global geospatial infrastructure (see below). For instance, the VLBI slew rate (the speed at which the telescope can rotate to track 
extraterrestrial sources) at Hobart is currently slower than international VLBI telescopes, thus preventing it from providing comparable amounts of data. Therefore, a component of the AuScope funding is to be directed towards upgrading the existing infrastructure, thus providing an international standard set-up.

\subsection{Australia's contribution to international science}

Australia is a significant landmass in the Southern Hemisphere with a developed economy. As such, it is better-placed to contribute to the global geospatial infrastructure than most other Southern Hemisphere countries. At present, many geodetic observatories are concentrated in North America and Europe, which is not an optimal scenario for global studies. Adding to the existing global infrastructure will allow Australia to play a more dominant role in international campaigns.

In 2005, the International Association of Geodesy (IAG) launched the Global Geodetic Observing System (GGOS), an international initiative with a central scientific theme of "global deformation and mass exchange processes in system Earth" (Drewes and Reigber, 2005; Pearlman et al., 2002). This encompasses the global patterns of tectonic deformation, all types of height changes, deformation due to the mass transfer between atmosphere, hydrosphere including ice and solid Earth, the separation of effects of mass changes from motion and from thermal expansion, separation of ocean effects from solid Earth effects (i.e., "absolute" sea level), quantification of angular momentum exchange, and mass transfer.

These broad goals will be achieved by endeavours to maintain the stability of timeseries of geometric and gravimetric reference frames, ensuring the consistency between the different geodetic standards used in the geoscience community, improving analysis models at the level required by the observations, and focusing on all aspects to ensure the consistency of geometric and gravimetric products. The geospatial infrastructure to be acquired through AuScope meshes directly into that required to address the global objectives of GGOS, objectives that are just as pertinent to Australia as they are to the international community. (Detailed information about GGOS can be found at http://ggos.gfz- 
potsdam.de/ggos/index.php?id=52).

The AuScope infrastructure will also allow Australia to contribute more than it already does to the IAG's services, in particular the International GNSS Service (IGS; Moore and Neilan, 2005), International VLBI Service (IVS; Schlüter and Behrend, 2007), and the International SLR Service (ILRS: Pearlman et al., 2002). Of most practical relevance to the larger number of users in Australia is the supply of GNSS data to the IGS. This permits the computation of precise satellite orbits and clock parameters that allow for precise point positioning (PPP; Zumberge et al., 1997), and lies behind the AUSPOS service (http://www.ga.gov.au/geodesy/sgc/wwwgps/). The provision of high quality and higher data rate data to these services will ultimately lead to better reference frame definition both globally and in the Australian region (cf. Altamimi et al., 2007).

\subsection{Preparing for the Future}

Addressing the geospatial science questions of the next decade requires an order of magnitude improvement in the accuracy of geodetic analyses (Plag, 2005). Reference frames underpin all science endeavours and geospatial activities are fundamental components of any scientific study relying on geodetic observations. Indeed, many scientists rely on geodetic information, but give little thought to where it comes from. Only when the information is not available do they realise geodesy's key role. Both inertial (celestial) and terrestrial coordinate systems are needed. The inertial system is used primarily for orbit determinations, and the terrestrial system for expressing the position of sites on the Earth, the Earth's gravity field and other geodynamic phenomena.

Knowledge of the location of the spin axis of the Earth and its rotation about this axis is essential to connect the celestial and terrestrial reference frames (e.g., Gambis, 2004). Current limiting factors in many "cutting-edge" investigations lie in the reference frame definitions because the errors in definition of the coordinates of celestial bodies (cf. Titov, 2007), and the origin, scale and orientation of the terrestrial reference frames are of the same order of magnitude as the geophysical signals being studied (e.g., sea level rise). Therefore, it is of fundamental importance for Australia - and indeed the global 
community - to have the required infrastructure to define accurately the reference frames for all future geoscience and geospatial activities and applications.

\subsection{Omissions}

As the amount of funding available was limited, choices had to be made in terms of what infrastructure would not be requested. AuScope Geospatial contains no component of the DORIS (Doppler Orbitography and Radiopositioning Integrated on Satellite) system, because the Australian continent is already covered by three receivers at Yaragadee, Canberra and Port Moresby (DORIS satellites can only receive transmissions from up to two sites simultaneously) and the precision of the coordinate estimates is inferior to that of other GNSS systems (Williams and Willis, 2006; Le Bail, 2006). There is also no component of Interferometric Synthetic Aperture Radar (InSAR) - a technique that can be used to estimate ground deformation with high spatial resolution - nor funding for an additional, permanent SLR tracking station. However there were funds available to jointly run a test campaign at Burnie, Tasmania with the French team at L'Observatoire de la Cote d'Azur bringing their portable mobile laser system (FTLRS) to Tasmania for a period of 5 months (see SLR section below).

\section{The New Infrastructure}

Figure 1a shows the locations of existing infrastructure (as at April 2008) while Figure 1b shows the projected enhanced network of geospatial sites. Note that only the GNSS sites that comprise the ARGN operated by Geoscience Australia are shown in Figure 1a: there

are many State/Territory- and industry-operated permanent GNSS sites in addition to this, some of whom will contribute to the new national GNSS network.

\subsection{Very Long Baseline Interferometry}

The geodetic VLBI concept uses two or more radiotelescopes to simultaneously observe numerous extragalactic sources, mostly quasars (extremely bright and distant radio sources generated by a galaxy forming around a black hole), and the S- and X-band data are 
recorded and time-tagged, usually using Hydrogen masers. These time-tagged data are then correlated to generate fringes and thus obtain the delay observable. From these delays, the baseline lengths to millimetric precision and other geodetic parameters (e.g., Earth rotation and orientation) can be deduced. VLBI provides the most precise measurement of distance over very long $(1,000+\mathrm{km})$ ranges, thus providing scale to the TRF.

Three new VLBI stations will be installed/upgraded in Australia, with three 12mdiameter telescopes equipped with $\mathrm{S} / \mathrm{X}$-band receiver systems, Mark 5B+ recorders and Hydrogen maser time and frequency standards. The first new system will replace the existing telescope at Hobart and will significantly increase the tracking capabilities through faster slew rates. The second system will be installed in Western Australia, co-located with the existing SLR and GNSS systems at Yaragadee. The third system will establish a new fundamental geodetic site in the Northern Territory near Katherine. These three new VLBI systems will be complemented by geodetic observations on the existing 64m-diameter telescope at Parkes (NSW) and also the new installation in New Zealand (In June 2008, Auckland University of Technology will install a new Patriot telescope to conduct geodetic VLBI observations). Figure 2 shows a $12 \mathrm{~m}$ Patriot antenna such as has been ordered for installation at Hobart.

Electronic hardware will be developed and tested on the Hobart system before being deployed at the other two Australian VLBI sites. It is anticipated that the Hobart system will become operational during 2009, with the other two sites to follow in 2009/10. These major enhancements of the global VLBI network will lead to significant improvements in the accuracy of the celestial reference frame in the Southern Hemisphere (cf. Titov, 2006).

NCRIS has provided funding for dedicated geodetic VLBI experiments for 180 days/year. At other times, the telescopes are available for scientific research (e.g., radio astronomy) and/or other purposes, but they must not compromise the geodetic programmes. To obtain access to the instruments, one needs to submit a proposal to the Chair of the Geospatial VLBI subcommittee (john.dickey@utas.edu.au). 
A new software-based VLBI correlator, a unique instrument in the world that is dedicated to geodetic VLBI processing, will be acquired in the form of a cluster of computers running software correlation code in a highly parallel fashion. This makes real-time correlation of VLBI data a reality, permitting instantaneous checking of data quality and equipment functionality (this currently occurs with a delay of weeks to months).

Previously, VLBI data had to be 'mechanically' correlated, where the fringes were time-tagged and recorded onto tapes that were sent to the main correlation facility in Bonn (Germany). As well as causing long time delays, the uncertainty that the VLBI data collected was useable could cause problems in scheduling VLBI observation campaigns. On the international stage, this is problematic because most VLBI telescopes are also used for radio astronomy, so there are time-scheduling constraints. Having the capability of near-real-time software correlation streamlines this process and will lead to more efficient use of the global infrastructure. Reliable, high bandwidth communication links are required before real-time correlation is possible. Funding is not currently identified for this purpose; therefore, the realisation of actual real-time geodetic VLBI remains a future goal.

\subsection{Gravity}

Gravimetry (the measurement of gravity) can be achieved in absolute and relative modes. Absolute gravimetry uses timed measurements of a free-falling proof mass. An optical laser interferometer measures the free-fall acceleration of a retroreflector in a vacuum, so is directly referenced to atomic standards of length and time. The precision of these instruments are $1-2 \mu \mathrm{Gal}\left(1 \mu \mathrm{Gal}=10^{-8} \mathrm{~m} / \mathrm{s}^{2}\right.$, equivalent to around $3-6 \mathrm{~mm}$ in height), and require a stable base and careful monitoring and modelling of local mass changes (e.g., groundwater). A relative technique that will be used in AuScope Geospatial is a relative Earth-tide gravimeter, which gives temporal changes in gravity at a site, but which is not tied to an absolute standard (unless co-located with an absolute gravimeter). Changes in gravity are inferred from measuring changes of a proof mass suspended by a zero-length spring (manufactured to disobey Hooke's law). 
The superconducting gravimeter at Mt Stromlo operates continuously and data have been used to detect the splitting of normal modes (e.g. Rosat et al., 2006) and excitation of the Earth's free oscillations (e.g. Nawa et al., 2000). The instrument was originally installed by the National Astronomical Observatory of Japan, Mizusawa, as part of the Ocean Hemisphere Network. * It is a component of the Global* Geodynamics Project (GGP) worldwide network of superconducting gravimeters Crossley et al., 1999) and now forms part of the AuScope geospatial infrastructure.

An FG-5 absolute gravimeter has been purchased and is currently undergoing preliminary testing before the commissioning of the instrument (Figure 3). Observations will then commence, starting in Canberra with observations at Mt Stromlo (co-located with the superconducting gravimeter) and Tidbinbilla at a site where FG-5 observations have been made previously. A comprehensive observation program will then be undertaken at selected sites across Australia. A relative tide meter, known as a gPhone, will be purchased in mid-2008 and will be used to quantify periodic signals associated with ocean tide loading.

\subsection{GNSS}

GNSS will continue to be the principal means by which users access the terrestrial reference frame (TRF); therefore, a nation-wide distributed network of sites is required. GNSS are also the fundamental measurement systems for the delivery of data to a wide range of application areas, such as crustal monitoring, meteorological products, spatial location systems (e.g., transportation).

Such a network in Australia will be of great benefit to a number of users: the stations will allow for improved orbit determination through the IGS, thus improving positioning in Australia; the stations can be used in the AUSPOS data processing service, again improving accuracy for Australian users. The network can be configured to generate realtime differential GPS corrections, again improving accuracy to users. Ultimately, it is feasible that all Australians will have the capability to position themselves accurately to a few centimetres anywhere and at any time. 
The volume of GNSS infrastructure required to suit all scientific applications was well beyond the scope of the NCRIS bid (e.g., GNSS stations to suit atmospheric tomography are optimally placed at a $5 \mathrm{~km}$ spacing while neotectonics studies would likely require a $15 \mathrm{~km}$ spacing, in order to detect surface deformation associated with small, intra-plate earthquakes such as occur in Australia (Dawson and Tregoning, 2008). Clearly, this is impractical as it would require the installation of thousands of CORS GNSS receivers across Australia (working on an estimate of $\$ 70 \mathrm{k}$ per station, this would cost well over $\$ 70 \mathrm{M}$ ). It was also recognised that existing non-geodetic GNSS networks already exist in Australia and are complementary to the proposed network for some applications. Therefore, a two-pronged approach was suggested.

The first component was the densification of the national geodetic GNSS network. The design of this network is based on several considerations: transects spanning the continent for measuring intra-plate deformation; circum-continental coverage for measuring vertical motion of tide gauges for sea level variation studies; major road/rail routes and mining and agricultural regions covered; major population areas and regions of specific environmental research. It will span some existing mining areas, although it is anticipated that the number of sites will be augmented by mine operators adding their own sites to the network in a collaborative venture. The second component is the facilitation of secondary or collaborative networks to be included into this system. This is broadly termed "Network Unification". Some elements of this have already begun, but much work is still required in this regard. Issues such as monumentation and sampling intervals will need to be addressed.

Data from the GNSS network will be available (at no cost to users) with a delay. The possibilities and process of obtaining data in real-time are discussed in Higgins (2008). The equipment will not be made available for specific user applications or research projects; rather, it will be installed and will operate under the control of the relevant government departments, who are also organising the rollout of the network, land access, etc., and contributing the majority of funds (in co-investment) for the acquisition of the equipment 
and operating costs.

\subsection{Satellite Laser Ranging}

Satellite laser ranging (SLR) involves transmitting laser pulses at reflectors fitted to Earthorbiting satellites. The time it takes for the pulses to return to the transmitter provides information on the distance between the laser and the satellite and is used to estimate the orbits of the satellites. Using a network of global SLR stations allows for the geocentre (the centre of mass of the Earth) to be determined.

There were two minor components to the requested infrastructure related to SLR:

- Upgrade of the SLR system at Mt Stromlo to enhance the ability of the system to range to high-orbit satellites. This has been completed and now permits more successful ranging to GNSS satellites, thereby contributing to the calibration/validation of GNSS orbit estimation.

- Testing of a mobile French Transportable Laser Ranging System (FTLRS) in Australia (Figure 4). The FTLRS (Nicholas et al., 2001) is an ultra- mobile SLR system that can be used to range to low-Earth orbiting satellites such as Jason-1, LAGEOSI, LAGEOS-II and AJISAI.

While simulations indicated that a third SLR station in northern Australia would significantly improve the precision of estimates of the origin and scale of the TRF, it was recognised that there would not be sufficient funds in the first NCRIS round to acquire all of the infrastructure that was required for Australia. Instead, the option of a mobile SLR system that could be deployed on a semi-permanent basis (i.e., six-month deployments) was investigated, leading to the possible acquisition at a later date. Such a system could provide additional observations to constrain the orbit estimates of altimeter satellites (thereby improving sea level estimates) and also act as a third Australian site providing data to the global SLR network for the purposes of estimating the origin of the TRF.

The test of the FTLRS instrument began in Burnie in December 2007 and ran until the end of April 2008. A complementary part of the FTLRS instrument operating at 
Burnie is the use of offshore oceanographic moorings, GPS buoy campaigns and tide gauge measurements to precisely measure the ocean surface at the same time as a Jason-1 and Jason-2 satellite altimeter overflights. This part of the experiment is being funded by another NCRIS capability, the Integrated Marine Observing System (IMOS). This is similar to work previously done by Watson it et al. $(2003,2004)$ for the TOPEX/Poseidon and Jason-1 altimeter satellites. Maintaining precision reference frames and satellite orbits using SLR is paramount for establishing an accurate estimate of sea level change over time as well as providing a properly calibrated measurement system across multiple satellite altimeter missions. To date, inter-calibration and maintenance of high precision satellite altimeter measurement systems has spanned over 15 years.

\subsection{Computing}

AuScope has acquired and operates a linux cluster (a suite of computers capable of sharing the requirements of computing tasks) for geophysical studies. The geospatial component contributed $\$ 130 \mathrm{k}$ towards the hardware which amount to about $20 \%$ of the total cost. Known as Terrawulf II, the system replaces the first-generation 'Terrawulf' cluster and is expected to be operational by June 2008. It will then be available for use in computationally intensive research.

Terrawulf II is a networked cluster of commodity computers to provide convenient high-end computing power for a range of demanding geoscience problems. The cluster comprises 96 IBM x3455 dual-processor dual-core compute nodes (384 processor cores) with 8 GB ECC RAM connected by gigabit ethernet. Half of the cluster is also connected through higher speed Voltaire Infiniband switches, which extend the range of potential applications of the cluster to both 'tight' and 'loosely coupled' codes, and 24 of the nodes have 17GB RAM for larger memory jobs.

The Terrawulf II cluster will be integrated into the AuScope grid and used for simulation and analysis of terrestrial processes related to the Australian continent and a variety of geoscience data processing, as well as continuing development of inversion and data inference software. It can also be used for the analysis of geospatial data such as GNSS, 
InSAR, etc. Further information on the system and access policies and procedures can be found at http://rses.anu.edu.au/TerraWulf. In brief, potential users need to submit a research proposal, which is assessed for scientific merit. If approved, the user will be granted access and will be able to install their software and make use of the computing capabilities.

\section{Science Objectives for the next 5-10 years}

The philosophy behind the NCRIS process was to have the scientific community, industry and government departments inform the Australian Federal Government of the deficiencies in current infrastructure that needed to be addressed to enable Australian scientists to make significant contributions to present-day and, perhaps more importantly, future research. Below we describe some of the main scientific issues that drove the selection of the geospatial infrastructure to be acquired.

\subsection{Reference Frame Definition}

The orientation and scale of the TRF is defined most accurately from VLBI observations. The vast majority of telescopes are located in the Northern Hemisphere and Australia is positioned geographically to be able to make a very significant impact in VLBI analysis by upgrading existing infrastructure in Tasmania and South Australia, and installing new telescopes in Western Australia and the Northern Territory (Figure 1b). It is widely acknowledged in the international scientific community that the lack of VLBI telescopes in the Southern Hemisphere weakens the TRF. The increased baseline lengths with the proposed additional VLBI sites will deliver a factor of four improvement in formal accuracy of geodetic analyses (O. Titov, 2008, pers. comm.).

The new network (comprising N-S and E-W oriented baselines of a few thousand kilometres; Figure 1b) will permit - for the first time - accurate imaging and coordination of radio sources in the Southern Hemisphere (cf. Totov, 2007). This will lead to a significant improvement in accuracy of the International Celestial Reference Frame (ICRF) which, in turn, will improve the accuracy of the International Terrestrial Reference Frame 
(ITRF), provided that the Earth orientation parameters that link them are sufficiently well known (Gambis, 2004).

The origin of the TRF (nominally the geocentre) is defined most accurately from SLR, since the retroreflector-equipped satellites orbit with respect the geocentre SLR tracking of satellites remains important - in particular for satellite altimeter and space gravity missions, such as Jason-1 and the Gravity Field and Steady-State Ocean Circulation Explorer (GOCE; Johannessen et al., 2003), respectively. Some Global Positioning System (GPS) satellites are also equipped with retroreflectors and can now be routinely observed by the Mt Stromlo SLR instrument after a recent NCRIS-funded upgrade (see below).

With the most recent release of the ITRF, it was realised that there was a statistically significant rate of northward translation of the origin along the Z-axis (the spin axis) between ITRF2005 (Altamimi et al., 2007) and ITRF2000 (Altamimi et al., 2002). While small, the translation rate of $+1.8 \mathrm{~mm} / \mathrm{yr}$ has important ramifications for studies of global sea level and uplift rates (e.g, glacial isostatic adjustment in polar regions, monitoring the stability of tide gauges for sea level rise). To illustrate, our analysis shows that the uplift rate at Australia's Antarctic GNSS site at Davis can change from $+0.2 \mathrm{~mm} / \mathrm{yr}$ to -1.4 mm/yr, depending on whether our global GPS analyses are computed in ITRF2000 or ITRF2005, while Beckley et al. (2007) showed that the use of the ITRF2005 in the reduction of satellite altimetry estimates of sea surface heights caused rate changes of up to $1.5 \mathrm{~mm} / \mathrm{yr}$.

Argus (2007) suggested that the cause of the Z-translation rate lies in the SLR analysis and, in particular, in the changing geometry of the global tracking network. Clearly, this is a significant issue for all geodetic techniques, since the TRF on which geodetic analyses depend has its origin defined solely by SLR (Altamimi et al., 2007). Additional SLR sites in Australia should help contribute to the resolution of this issue and, using AuScope funds, we tested the performance of an ultra-mobile SLR system for improvement of satellite altimeter orbit definition and reference frame improvement over a 5-month campaign at Burnie, Tasmania (described earlier). 
International GNSSs currently consist of GPS, GLONASS and, within a few years, the European Galileo system. GNSSs do not currently contribute significantly to the fundamental definition of the origin, axis and scale of the ITRF (this may change in the future as satellite technologies and analysis methods improve). They can however provide a density of sites that allows the accurate modelling of reference frame deformation due to Earth processes such as continental tectonics.

Just as users of positioning will require mm-accurate locations, so Australian science and industry is going to require a dense network of gravity stations with sub-microgal accuracy in gravity values. An accurate geoid model is essential for defining "orthometric heights" (i.e., the height above the geoid), which is necessary for addressing such simple problems as knowing which way water will flow (e.g., Featherstone and Kuhn, 2006) . This is essential for precise irrigation and agriculture applications, coastal inundation studies (e.g., relating Lidar-derived ellipsoidal heights to sea levels) and ocean circulation studies ("sea surface topography" is the difference between sea surface height and the geoid; therefore, an accurate global geoid is required for surface ocean current estimation; Tapley et al., 2003).

Airborne gravimetry will make a contribution by providing data with a spatial resolution of around $8 \mathrm{~km}$ to $10 \mathrm{~km}$ in coastal zones, thereby filling in the detail for those offshore areas where marine gravimetry cannot reach and models cannot be derived from satellite altimetry due to uncertainties of ocean floor and coastal effects (cf. Hwang et al., 2006). This area is particularly critical to geoid solutions for Australia, as the SE Coast is both the most densely populated and most important to measure given the variations of the bathymetry in this region. Thus, a combination of airborne, high-precision relative gravity observations and absolute gravity observations is required.

Accurate estimates of gravity at discrete points will allow for a readjustment of the existing gravity network, so as to propagate these values through the entire Australian national gravity database. Long-period observations and/or repeat observations at discrete sites are also required to quantify contemporary temporal variations of the gravity 
field of Australia.

The highly successful Gravity Recovery And Climate Experiment (GRACE; Tapley et al., 2004) satellite gravimetry mission is producing significant improvements in models of the Earth's geoid (and its temporal variation) at $\sim 400 \mathrm{~km}$ length scales. The complementary GOCE mission (Johannessen et al., 2003) will be launched in September 2008, and it is expected that other missions will follow. Therefore, significant investment in space gravity infrastructure is being made by other countries. Australia can contribute by providing accurate high-resolution regional gravity models for calibrating the space-derived models. This needs good long-wavelength control of terrestrial gravity networks, which can be provided by a carefully and accurately observed reference network of absolute and relative gravity data.

\subsection{Time-dependent Variations in Sea Level}

The average rate of global mean sea level rise for the period $1961-2003$ is $1.8+/-0.5$ mm/yr (IPCC, 2008) and a significant acceleration in sea level has recently been suggested (Church and White, 2006). The more recent period of sea level change, from 1993-2003, has been measured using satellite altimetry, with a global average rate of sea level rise of $3.1+/-0.7 \mathrm{~mm} / \mathrm{yr}$, although with distinct regional variations (Church et al., 2004). During the 21st century, sea level is projected to rise at a faster rate than during 19612003. Under the various climate change scenarios, by the mid-2090s for instance, global sea level is expected to reach 0.2-0.6 m above 1990 levels.

Monitoring and quantifying the spatial changes in sea level is going to be critical for Australia and its surrounding island nations. As a rule-of-thumb using the Bruun factor, the projected sea level rise and coastal recession are in the ratio of about 1:100-1000, depending on various factors. Thus, the projected sea level rise translates to $20-600 \mathrm{~m}$ of shoreline recession, a serious coastal management issue for the future.

Estimates of relative sea level change were typically derived from tide gauge records but, more recently, tide gauge measurements as well as satellite altimetry observations and in-situ measurements of the ocean's temperature and salinity (via Argo floats and 
expendable bathythermograph (XBT) profiles) have been used to quantify the global ocean's thermosteric change.

Measurement techniques at tide gauges and from satellite altimetry depend heavily on the TRF for the following reasons:

- Tide gauges measure relative sea level and it is not possible to discern whether a change is caused by rising/falling heights of the oceans or of the land to which the tide gauge is fixed. Tide gauges in some locations are actually rising by up to 8 mm/yr because of land movement (e.g., Churchill Bay in Canada). Such motion must be measured and removed from tide gauge records before accurate absolute sea level change can be extracted from tide gauge observations. This requires geodetic techniques to monitor the motion of the land relative to the geocentre. A colocated GNSS installation is required at principal tide gauge sites along with regular measurements of relative height between the GNSS installation and the tide gauge.

- Satellite altimetry is the measurement of the distance from the satellite to the ocean surface. If the orbit of the satellite is known accurately, then the height of the ocean (relative to the geocentre) can be estimated. Errors in the position of the satellite altimeter orbit propagate directly into values of sea surface heights. Satellite altimeter missions also have limited life spans (typically 5-7 years); therefore, the long-term (climate) estimates of sea level change from altimetry depends entirely on the ability to ensure continuity in the estimates of the orbits of the altimeters and calibration of the various altimeters. This, in turn, depends on an accurate definition of the TRF. Ongoing calibration/validation of altimeters is required such as has been done recently at Burnie in Tasmania, the only Southern Hemisphere calibration/validation site (Watson et al., 2003, 2004).

\subsection{Intra-plate Deformation of the Australian Continent}

The [solid] Earth deforms on timescales ranging from seconds/minutes (during an earthquake), hours/days (tidal deformation) up to decades/centuries (plate tectonics, glacial 
isostatic adjustment). Intra-plate earthquakes occur regularly within the Australian Plate (e.g., Denham, 1988), however we do not yet have sufficient scientific data to model the strain pattern of the Australian continent. Seismic hazard and its economic effect on building codes, insurance costs, etc. is an important issue for Australian society. Coupled with the over-arching network of VLBI sites, the deformation field imaged from direct measurements of relative motion across Australia from networks of GNSS sites - along appropriately chosen transects - will contribute to mapping the seismic hazards of the Australian continent. Strain rate estimates from the analysis of the GNSS data will provide critical input information into the numerical deformation models that have been/will be developed through the AuScope project. These estimates will become available once the GNSS network is densified and several years of data will have been observed.

The continental deformation pattern of Australia is very poorly known at this stage. One could blanket the country with a dense (and expensive) network of GNSS sites, thereby capturing both signals of deformation and also, potentially, large areas of no deformation. In an attempt to improve the current, rather ignorant state of knowledge, dense networks on several transects across the country - along major transport routes - will be observed as well as targeted, currently active seismic areas (e.g., SW Seismic Zone in WA, Flinders Ranges in SA, Tennent Creek in NT). The results of the proposed transects and targeted areas will provide some information where little currently exists and will guide scientists in the future for refining the areas for further detailed study. Furthermore, the decision to align transects with major transport routes means that the same infrastructure can be used to support real-time positioning applications and will cover $90 \%$ of likely users.

Short-period deformation of the Earth occurs elastically on sub-daily to sub-weekly time scales and causes the physical locations of geodetic tracking sites to move by 1-10 $\mathrm{mm}$ (atmospheric pressure loading), up to $35 \mathrm{~mm}$ (ocean tide loading) and up to $400 \mathrm{~mm}$ (solid Earth tide deformation). These motions must be modelled and/or independently measured in the analysis of the geodetic data; failure to do so leads to aliasing of sub- 
daily periodic signals into artificial signals at many other frequencies (including annual, semi-annual) that then feeds negatively into orbit estimation, long-term trend analyses, etc. (e.g., Stewart et al., 2005; Watson et al., 2006). Models exist for several geophysical effects that deform the Earth elastically such as the solid Earth tide, ocean tide loading, atmospheric pressure loading etc. Models for the former have not been tested at the $1 \%$ level (the anelastic component), while none of the models for the latter effects are globally accurate at the $1 \mathrm{~mm}$ level required for the next decade. Significant research effort is needed here, requiring geodetic infrastructure located in regions sensitive to these deformations so that new models can be developed, calibrated and tested.

Continuous gravity measurements can provide accurate information on the actual ocean tide loading effects at geodetic sites - in particular, near-coastal sites. The most accurate approach for measuring terrestrial gravity changes is through the highly precise superconducting gravimeter, augmented by absolute (FG5) gravity measurements to control the drift of the relative instruments (van Camp et al., 2005). With such an approach, ocean tide loading models for each co-located tide gauge/GNSS site could be determined. This will lead to improvements in the modelling of sub-daily periodic effects in the analysis of positioning data, leading to reductions in known aliasing of these signals into other frequencies (e.g., Penna and Stewart, 2003; Stewart et al., 2005); hence, will improve the accuracy of the coordinates of the national fundamental reference sites and sites co-located with tide gauges.

\subsection{Oceanographic and Cryospheric Studies}

The geocentric radius to the surface of the land and sea is a changing quantity at each point on the Earth. Tidal forces, wind stress and atmospheric pressure constantly remold the sea surface. These changes can be progressive, cyclic or intermittent, but each has an explanation and significance in further understanding of physical processes at work within the solid Earth, oceans and atmosphere. The measurement of the difference between the topography of the sea surface and the geoid (cf. Tapley et al., 2003) provides information on ocean currents, circulation and long-term trends in sea levels. 
What can we predict for 2010 and 2100 about the state of the ocean and cryosphere? Definition and improvement in the geoid is required to define "absolute" surface geostrophic currents and understanding of barotropic and baroclinic contributions in ocean circulation. Changes in the cryosphere and subsequent contributions to the global sea level budget need to be addressed from combinations of vertical motions estimated from GPS, in-situ gravity, in-situ field campaigns and satellite gravity and altimetry to detect mass balance changes. Satellite-based methods will be used to map ice extent and snow accumulation (scatterometers), monitor river and lake levels from space (radar altimetry).

Water is a very valuable resource for Australia and geodesy can observe changes in components of water storage. Such information will contribute to knowledge of the hydrological cycle and land-water storage (soil moisture, ground water, snow depth, surface waters). Ground-based infrastructure can validate and augment space-based observations. Overall, such studies will reduce the uncertainties for climate forecasting and enable managers to make more educated decisions for strategic planning and adaptation measures.

\section{Progress To Date}

As at April 2008, significant progress has been achieved in the acquisition and commissioning of the geospatial infrastructure:

- A contract has been signed for the purchase of the first VLBI telescope, with delivery likely in early 2009. Orders are about to be placed for a Mark 5B+ recorder for Hobart plus Mark 5B+ playbacks for the VLBI correlator.

- A suitable site has been selected in the Northern Territory for the VLBI installation, subject to an acceptable geotechnical survey (that is yet to be undertaken).

- A 120 core Beowulf cluster has been installed in Western Australia as the platform on which the VLBI software correlator (DiFX) will run. The correlator output has been verified against the trusted geodetic MarkIV correlator at the Max Planck Institute for Radioastronomy in Bonn, Germany, confirming that DiFX can be used 
for geodetic VLBI (Tingay et al. manuscript in preparation).

- A FG-5 absolute gravimeter was delivered in March 2008, and is underoing tests. An order for a gPhone relative tidal gravimeter will be placed by mid-2008.

- The SLR system at Mt Stromlo has been upgraded. Initial observations with the enhanced system show that returns from GPS satellites have been improved.

- The testing of the FTLRS was successfully undertaken at Burnie from December 2007 to April 2008. The observations are currently being analysed for consistency and relative accuracy improvement.

- Three new GNSS sites have been installed in Western Australia and two new sites in Tasmania. The densification of the continent-wide network (Figure 1b) is ongoing, under the management of Geoscience Australia and State/Territory government departments.

\section{Concluding Remark}

The process of acquiring, installing and commissioning the new infrastructure has commenced. At this stage only around $10 \%$ of the total NCRIS funding for geospatial infrastructure has been spent, although considerable co-investment has already occurred through State/Territory government departments preparing for the GNSS network. Administrative and scientific structures are in place to oversee the acquisition process and the ongoing rollout of the equipment is underway. It is anticipated that, by the end of 2010, the proposed network of geospatial infrastructure shown in Figure $1 \mathrm{~b}$ will be in place and operational, opening the possibility of undertaking the scientific studies described above, as well as others.

The purpose of this paper is to raise awareness in the Australian and international community of the considerable investment that is underway to enhance Australia's geospatial infrastructure. Certain facets of the AuScope geospatial project are led by the university 
sector (e.g., VLBI) while other parts are almost exclusively led by government departments (e.g., GNSS). Even though not documented in this paper, the contributions of institutions (in particular, State/Territory and Federal departments) in terms of co-invested equipment, operating costs and personnel are significant and will make the geospatial component of AuScope successful.

Acknowledgements We are grateful to all participants of the AuScope team who contributed to the successful bid of capability area 5.13 and to the Australian State and Federal Governments for providing the funding to enhance the geospatial infrastructure of Australia for future generations. R. Twilley provided the coordinates for the proposed GNSS sites. We would like to thank the co-authors who contributed to the development of the geospatial science case (upon which this paper is based) and also thank in advance the many people and government agencies who will contribute to the development, installation and operation of the infrastructure into the future.

\section{References}

Altamimi, Z., Collilieux, X., Legrand, J., Garayt, B. and Boucher, C. (2007) ITRF2005: A new release of the International Terrestrial Reference Frame based on time series of station positions and Earth Orientation Parameters, Journal of Geophysical Research - Solid Earth, vol. 112, art. B09401, doi:10.1029/2007JB004949.

Altamimi, Z., Sillard, P. and Boucher, C (2002) ITRF2000: a new release of the International Terrestrial Reference Frame for Earth science applications, Journal of Geophysical Research - Solid Earth, vol. 107, no. B10, art. 2214, doi: 10.1029/2001JB000561.

Argus, D.F. (2007) Defining the translational velocity of the reference frame of Earth, Geophysical Journal International, vol. 169, no. 3, pp. 830-838, doi: 10.1111/j.1365246X.2007.03344.x

Beckley, B.D., Lemoine, F.G., Luthcke, S.B., Ray, R.D. and Zelensky, N.P. (2007) A reassessment of global and regional mean sea level trends from TOPEX and Jason-1 
altimetry based on revised reference frame and orbits, Geophysical Research Letters, vol 34, doi:10.1029/2007GL030002.

BearingPoint (2004) National geodetic infrastructure requirements study, NRCan 030628 Final report, Dec. 22 2004, Natural Resources Canada, Ottowa.

Church, J.A. and White, N.J. (2006) A 20th century acceleration in global sea-level rise, Geophysical Research Letters, vol. 33, L01602, doi:10.1029/2005GL024826.

Church, J.A., White, N.J., Coleman, R., Lambeck, K. and Mitrovica, J.X. (2004) Estimates of the regional distribution of sea level rise over the 1950 - 2000 period, Journal of Climate 17(1): 2609-2625, doi: 10.1175/1520-0442(2004)017;2609:EOTRDO ¿2.0.CO;2.

Crossley D., Hinderer J., Casula G., Francis O., Hsu H.-T., Imanishi Y., Jentzsch G., Kaarianen J., Merriam J., Meurers B., Neumeyer J., Richter B., Shibuya K., Sato T., and van Dam, T. (1999) Network of superconducting gravimeters benefits several disciplines, EOS - Transactions of the American Geophysical Union, vol. 80, pp. 121-126.

Denham D. (1988) Australian seismicity - the puzzle of the not-sostable continent. Seismological Research Letters, vol. 59, pp. 235-240

Drewes, H. (2005) The Global Geodetic Observing System (GGOS) of the International Association of Geodesy (IAG). FIG Working Week 2005 and GSDI - 8, Cairo, Egypt, 18.04.2005

Featherstone, W.E. and Kuhn, M. (2006) Height systems and vertical datums: a review in the Australian context, Journal of Spatial Science, vol. 51, no. 1, pp. 21-42.

Gambis, D. (2004) Monitoring Earth orientation using space-geodetic techniques: state-of-the-art and prospective, Journal of Geodesy, vol. 78, nos. 4-5, pp. 295-303, doi: 10.1007/s00190-004-0394-1

Higgins, M.B. (2008) An organisational model for unified GNSS reference station network for Australia, Journal of Spatial Science (this issue)

Hwang, C., Guo, J., Deng, X., Hsu, H-Y. and Liu, Y. (2006) Coastal gravity anomaly from retracked Geosat/GM altimetry: improvement, limitation and the role of airborne gravity data, Journal of Geodesy, vol. 80, no. 4, pp. 204-216, doi: 10.1007/s00190-062- 
0052-x.

Johannessen, J.J., Balmino, G., Le Provost, C., Rummel, R., Sabadini, R., Sünkel, H., Tscherning, C.C., Visser, P., Woodworth, P., Hughes, C.W., Legrand, P., Sneeuw, N., Perosanz, F., Aguirre-Martinez, M., Rebhan, H. and Drinkwater, M.R. (2003) The European Gravity Field and Steady-State Ocean Circulation Explorer Satellite Mission: Impact in Geophysics, Surveys in Geophysics, vol. 24, no. 4, pp. 339-386, doi: 10.1023/B:GEOP.0000004264.04667.5

Le Bail, K. (2006) Estimating the noise in space-geodetic positioning: the case of DORIS, Journal of Geodesy, vol. 80, nos. 8-11, pp. 541-565, doi: 10.1007/s00190-0060088-y.

Mitrovica, J.X., Tamisiea, M.E., Davis, J.L. and Milne, G.A. (2001) Recent mass balance of polar ice sheets inferred from patterns of global sea-level change, Nature, vol. 409, no. 6823, pp. 1026-1029, doi: 10.1038/35059054.

Moore, A.M and Neilan, R.E. (2005) The International GPS Service tracking network: enabling diverse studies and projects through international cooperation, Journal of Geodynamics, vol. 40, nos. 4-5, pp. 461-469, doi: 10.1016/j.jog.2005.10.009.

Nawa K, Suda, N., Fukao, Y., Sato, T., Tamura, Y., Shibuya, K., McQueen, H., Virtanon, H. and Kaariainen, J. (2000) Incessant excitation of the Earth's free oscillations: global comparison of superconducting gravimeter records, Physics of the Earth and Planetary Interiors, vol. 120, no. 4, pp. 289-297, doi: 10.1016/S0031-9201(00)00158-8

Nicholas, J., Pierron, F., Samain, E. and Barlier, F. (2001) Centimeter accuracy for the French Transportable Laser Ranging System (FTLRS) through sub-system controls, Surveys in Geophysics, vol. 22, nos. 5-6, pp. 449-464, doi: 10.1023/A:1015612032752.

Pearlman, M.R., Degnan, J.J. and Bosworth, J.M. (2002) The International Laser Ranging Service, Advances in Space Research, vol. 30, no. 2, pp. 135-143, doi: 10.1016/S02731177(02)00277-6.

Pearlman, M., Altamimi, Z., Beck, N., Forsberg, R., Gurtner, W., Kenyon, S., Behrend, D., Lemoine, F.G., Ma, C., Noll, C.E., Pavlis, E.C., Malkin, Z., Moore, A.W., Webb, F.H., Neilan, R.E., Ries, J.C., Rothacher, M. and Willis, P. (2006). Global geodetic observing 
system - considerations for the geodetic network infrastructure, Geomatica, vol. 60, no. 2, pp. 193-204.

Penna, N.T and Stewart, M.P. (2003) Aliased tidal signatures in continuous GPS height time series, Geophysical Research Letters, vol. 30, 2184, doi:10.1029/2003GL018828.

Plag, H.-P. (2005), The GGOS as the backbone for global observing and local monitoring: A user driven perspective, Journal of Geodynamics, 40, 479-486.

Rosat, S., Sato, T., Imanishi, Y., Hinderer, J., Tamura, Y., McQueen, H. and Ohashi, M (2005) High-resolution analysis of the gravest seismic normal modes after the $2004 \mathrm{M}_{w}$ $=9$ Sumatra earthquake using superconducting gravimeter data, Geophysical Research Letters, vol. 32, art. L13304, doi:10.1029/2005GL023128.

Schlüter, W. and Behrend, D. (2007) The International VLBI Service for Geodesy and Astrometry (IVS): current capabilities and future prospects, Journal of Geodesy, vol. 81, nos. 6-8, pp. 379-387, doi: 10.1007/s00190-006-0131-z.

Stewart, M.P., Penna, N.T. and Lichti, D.D. (2005) Investigating the propagation mechanism of unmodelled systematic errors on coordinate time series estimated using least squares, Journal of Geodesy, vol. 79, no. 8, pp. 479-489, doi: 10.1007/s00190-0050478-6.

Tapley, B.D., Chambers, D.P., Bettadpur, S. and Ries, J.C. (2003) Large-scale ocean circulation from the GRACE GGM01 geoid, Geophysical Research Letters, vol. 30, no. 22, doi: 10.1029/2003GL018622.

Tapley, B. D., Bettadpur, S., Watkins, M. and Reigber, C. (2004) The gravity recovery and climate experiment: mission overview and early results, Geophysical Research Letters, vol. 31, art. L09607, doi: 10.1029/2004GL019920

Titov, O. (2007) Effect of the selection of reference radio sources on geodetic estimates from VLBI observations, Journal of Geodesy, vol. 81, no. 6-8, pp. 455-468, doi: 10.1007/s00190-007-0145-1.

Van Camp, M., Williams, S.D.P. and Francis, O. (2005) Uncertainty of absolute gravity measurements, Journal of Geophysical Research, vol. 110, art. B05406, doi: 
10.1029/2004JB003497.

Watson, C.S, Coleman, R., White, N.J., Church, J.A. and Govind, R (2003) Absolute Calibration of TOPEX/Poseidon and Jason-1 using GPS Buoys in Bass Strait, Australia, Marine Geodesy, vol. 26, nos. 3-4, pp, 285-304.

Watson, C.S, White, N.J., Coleman, R., Church, J.A., Morgan P. and Govind, R (2004) TOPEX/Poseidon and Jason-1: Absolute Calibration in Bass Strait, Australia, Marine Geodesy, vol. 27, nos. 1-2. pp, 107-131.

Watson, C., Tregoning, P. and Coleman, R (2006) The impact of solid Earth tide models on GPS time series analysis, Geophysical Research Letters, vol. 33, no. 8, art. L08306, doi: 10.1029/2005GL025538.

Williams, S.P.D. and Willis, P. (2006) Error analysis of weekly station coordinates in the DORIS network, Journal of Geodesy, vol. 80, nos. 8-11, pp. 525-539, doi: 10.1007/s00190-006-0056-6.

Zumberge J.F, Heflin, M.B., Jefferson, D.C., Watkins, M.M. and Webb, F.H. (1997) Precise point positioning for the efficient and robust analysis of GPS data from large networks, Journal of Geophysical Research, vol. 102, no. B3, pp. 5005-5017. 


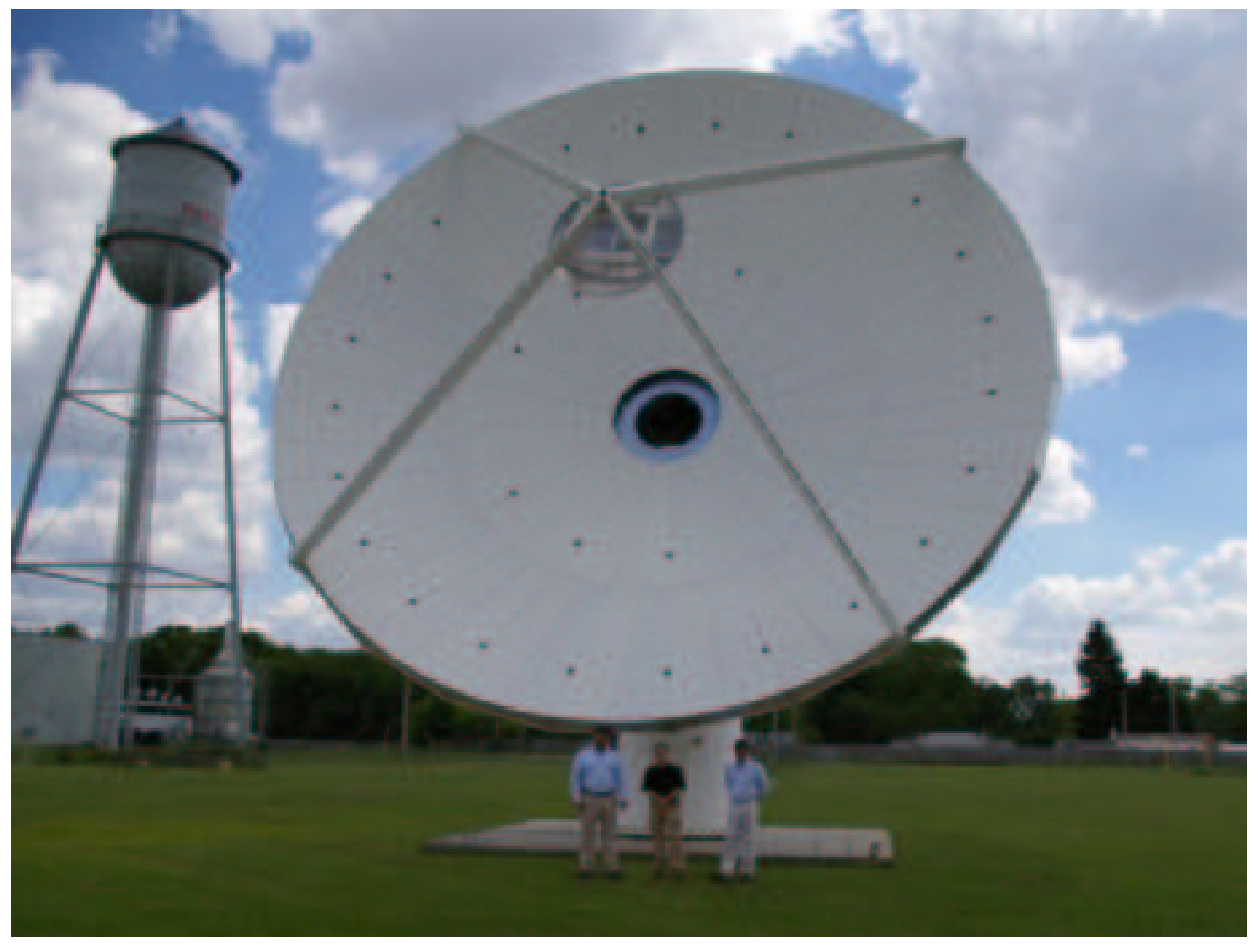

Figure 2: A Patriot $12 \mathrm{~m}$ antenna similar to that which has been ordered for installation at Hobart. Photo courtesy of Patriot Antenna Systems Inc. 
Figure 3: The new Australian FG-5 absolute gravimeter. 


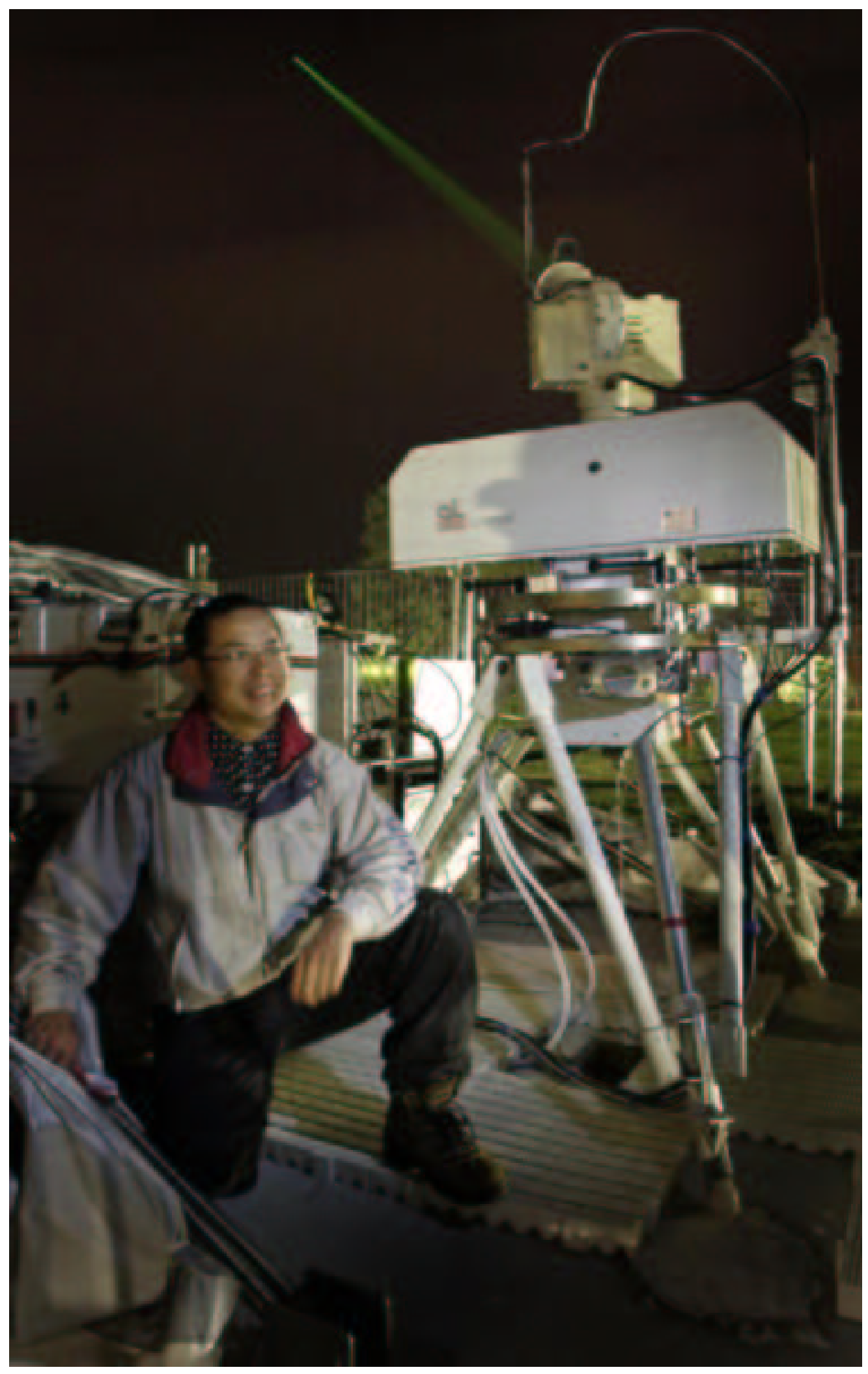

Figure 4: The French Transportable Laser Ranging System (FTLRS) in operation at Burnie. Photo: C. Kidd. 